\title{
Familial thoracic aortic aneurysm and aortic dissection
}

INSERM

\section{Source}

INSERM. (1999). Orphanet: an online rare disease and orphan drug data base. Familial thoracic aortic aneurysm and aortic dissection. ORPHA:91387

Familial thoracic aortic aneurysm and aortic dissection is a rare genetic vascular disease characterized by the familial occurrence of thoracic aortic aneurysm, dissection or dilatation affecting one or more aortic segments (aortic root, ascending aorta, arch or descending aorta) in the absence of any other associated disease. Depending on the size, location and prog ression rate of dilatation/dissection, patients may be asymptomatic or may present dyspnea, cough, jaw, neck, chest or back pain, head, neck or upper limb edema, difficulty swallowing, voice hoarseness, pale skin, faint pulse and/or numbness/ting ling in limbs. Patients have increased risk of presenting life threatening aortic rupture. 